\section{Randomized study to compare efficacy of short stretch bandage systems from KOB with locally used Cotton Crepe Bandages in the treatment of lower limb lymphoedema}

Anita Dhar, Anurag Srivastava, M.C. Misra

Department of Surgical Disciplines, AIIMS, New Delhi, India

\section{Aims and Objectives}

Primary Objectives: To assess and compare the effectiveness of the KOB short stretch bandage (530) with multilayer local cotton crepe compression bandage system in the treatment of lower limb lymphoedema.

Secondary Objectives: To assess and compare the following parameters between the two arms of the study: Decrease in Swelling, Pain during walking, Quality of life, Handling of bandage, Ease of use.

\section{Patients and Methods}

Patients affectd by leg lymphedema were randomly assigned to receive short stretch bandage (treament group) or a local cotton crepe compression (control group).

\section{Inclusion criteria}

Male/Female patients of age 18 and above suffering from lower limb, secondary lymphoedema were included.

\section{Exclusion criteria}

Patients suffering from arterial disease or undergoing additional therapy/treatment.

\section{Intervention or therapy arms}

Patients in the therapy arm were treated with a bandage system comprising of stockinette + cotton role $+\mathrm{KOB}$ short stretch bandage.

\section{Control arm}

Patients in the control arm were treated with cotton role and stockinette along with local cotton/crepe bandages.

Bandage application was done by trained staff. They ensured through a Picopress ${ }^{\circledR}$ that a $40 \mathrm{~mm} \mathrm{Hg}$ sub bandage pressure was obtained. Patients were called for revaluation of sub-bandage pressure signs of slippage with retying as required. Girth charting was done at different levels of the limb in $\mathrm{cm}$. These were repeated with every bandage which was every week till the end of the first month. At the end of the month, patients were provided with short stretch bandages which were washable and could be reused. Further monitoring continued for another three months.

\section{Ethics Committee}

Cleared from the AIIMS ethics committee.

\section{Results}

Twelve of 72 patients found suitable after preliminary evaluation, did not consent. The balance 60 patients, randomized to 30 for each group consisted of 33 males and 27 females. Ages ranged between 18 to 60 years. Most had associated symptoms in the form of fever, inflammation, swelling, ulceration and pain in the legs. Duration of symptoms was minimum three months, but most were over five years. Showed partial
Correspondence: Anita Dhar, Department of Surgical Disciplines, AIIMS, New Delhi, India.

E-mail: dranitadharbhan@gmail.com

Conference presentation: International Compression Club (ICC) Meeting, Rotterdam, 2018

This work is licensed under a Creative Commons Attribution 4.0 License (by-nc 4.0)

(C) Copyright A. Dhar et al., 2018

Licensee PAGEPress, Italy

Veins and Lymphatics 2018; 7:7991

doi:10.4081/vl.2018.7991

or complete Lymphatic blockade in all.

Lymphedema was of significantly higher grade in the study group with four patients having florid Elephentiasis Baseline lab investigations were normal in all.

All patients improved in volume Average reduction in study group was $51.3 \%$ and in control group-37.75\% (NS). There was relief in pain in all and no affect on joint mobility. The only significant difference was a need of a higher number of bandages control arm (average seven) as compared to three for the study) to achieve the desired pressure. There was associated higher amount of slippage with need for reapplication. Compliance to the bandages was however good and equal in both the groups.

\section{Conclusions}

Both types of bandages can provide required pressure to effectively treat lymphoedema. 